\title{
Efficacy of Mefipristone for induction of labour in late term pregnancy
}

\author{
Roopa N. K., Rekha N.*
}

Department of Obstetrics and Gynaecology, BGS Global Institute of Medical College, Bengaluru, Karnataka, India

Received: 29 March 2019

Accepted: 06 May 2019

\section{*Correspondence:}

Dr. Rekha N.,

E-mail: karthikmana@gmail.com

Copyright: (c) the author(s), publisher and licensee Medip Academy. This is an open-access article distributed under the terms of the Creative Commons Attribution Non-Commercial License, which permits unrestricted non-commercial use, distribution, and reproduction in any medium, provided the original work is properly cited.

\section{ABSTRACT}

Background: Late-term pregnancy defined as one that has reached between $410 / 7$ weeks and $416 / 7$ weeks of gestation is associated with an increased maternal morbidity as well as an increased risk of fetal and neonatal mortality and morbidity. Mifepristone, an anti-glucocorticoid and antiprogesterone, though not an oxytocic increases uterine activity and causes cervical effacement and dilatation and improves the Bishop score without over/hyper stimulation of uterus. Increased maternal and fetal mortality from late term pregnancy could be prevented by induction of labour. The objective of this study was to know the efficacy of single dose of oral mifepristone in induction of labour in late term pregnancy and to assess the induction delivery interval in the study population.

Methods: This was a prospective interventional study conducted in Department of Obstetrics and Gynaecology at BGS Global Institute of Medical Sciences, Bengaluru. 100 Women with late term pregnancy who fulfilled the inclusion and exclusion criteria were considered for the study after an informed written consent.

Results: $73.5 \%(n=36)$ of multigravida and $80.4 \%(n=41)$ of prim gravida showed improvement in the Bishop score post induction with mifepristone and majority (89.79\% primigravida and $84.31 \%$ multigravida) of the study population had vaginal delivery. Multigravida (73.5\%) had less induction delivery interval (less than 48hours) compared to primigravida (19.6\%).

Conclusions: Mifepristone, a progesterone antagonist causes a significant improvement in the Bishop's score and is associated with an increased rate of vaginal deliveries.

Keywords: Bishops score, Late term pregnancy, Mifepristone, Vaginal delivery

\section{INTRODUCTION}

Late-term pregnancy is defined as one that has reached between $410 / 7$ weeks and $416 / 7$ weeks of gestation. ${ }^{1}$ Post term pregnancy is associated with an increased maternal morbidity as well as an increased risk of fetal and neonatal mortality and morbidity. ${ }^{2,3}$ Increased maternal and fetal mortality from late term pregnancy could therefore be prevented by induction of labour (IOL). Both clinicians and patients are concerned about the risks of induction of labour that includes uterine hyper-stimulation, failed induction and increased caesarean section rates. ${ }^{4}$ A recent Cochrane registry report suggests that induction of labour at 41 completed weeks' of gestation is associated with fewer perinatal deaths, and significantly fewer caesarean deliveries compared with expectant management. ${ }^{5}$ ACOG concludes that "Induction of labour between $410 / 7$ and $420 / 7$ weeks can be considered" given evidence of an increase in perinatal morbidity and mortality. ${ }^{5}$

Mifepristone a steroidal compound that has antiglucocorticoid and antiprogesterone action. It blocks the action of progesterone at the cellular level. ${ }^{6}$ It 
increases uterine activity and causes cervical effacement and dilatation. Mifepristone is rapidly absorbed and has a long half-life of 25-30 hours. ${ }^{7}$ As Mifepristone is not an oxytocic, it is not associated with over/hyper stimulation of uterus and hence there is no increased the incidence of rupture uterus. ${ }^{8}$ There are insufficient information available from clinical studies to support the use of Mifepristone to induce labour in late term pregnancy. Thus, based on the few clinical evidences which have used $200 \mathrm{mg}$ Mifepristone, our present study was conducted to find out the efficacy of Mifepristone for induction of labour in late term pregnancy. ${ }^{9}$

\section{METHODS}

An open label prospective interventional study was conducted in Department of Obstetrics and Gynaecology at BGS Global Institute of Medical Sciences, Bengaluru, India over a period of one year. The study was conducted on 100 women who were in their late term pregnancy.

During the study women were enrolled after fulfilling the inclusion and exclusion criteria. Pre induction modified Bishop's score was calculated. All benefits and risks associated with induction of labour with Mifepristone were explained to patients and relatives and a written consent for induction was taken.

\section{Inclusion criteria}

- Women with late term pregnancy with maternal age $>18$ years

- Singleton gestation

- Cephalic presentation

- Reactive FHR pattern in live fetus and intact membranes

- $\quad$ Preinduction Bishop's score $<5$

\section{Exclusion criteria}

- $\quad$ Estimated fetal weight $>4000$ grams or $<2,000$ grams

- Antepartum haemorrhage

- Previous caesarean section

- Chorioamnionitis

- Multiple pregnancy

- Term or preterm pregnancies with indications like gestational hypertension, gestational diabetes mellitus, intrauterine demise

\section{AIMS AND OBJECTIVES}

The aim of the study was to know the efficacy of single dose of oral Mifepristone 200mg for induction of labour in late term pregnancy. The objectives were,

- To study the efficacy of Mifepristone for induction of labour in study group by observing the improvement in Bishop Score.

- To observe the delivery outcome in the study group.
Women received one tablet mifepristone $200 \mathrm{mg}$ at the moment of enrolment on empty stomach. Pre induction Bishop Score calculated and scoring done after $24 \mathrm{hrs}$. And 48hrs later. Successful induction was defined as women who showed improvement in Bishop score and progressed to active labour within $24 \mathrm{~h}$ or 48 hours of induction $48 \mathrm{hrs}$ from the time of induction, if the women did not show improvement in Bishop score, they were categorised as cases of failed induction. Women with failed induction, fetal distress underwent caesarean section.

Women who entered active labour were augmented and delivered in accordance to our Centre recommendations.

\section{Statistical analysis}

In the present study, continuous variables were presented as mean with standard deviation. The Pearson Chi-square test has been performed to analyse proportions. The demarcating level of statistical significance was found at the probability level of 0.05 .

\section{RESULTS}

In the present study 100 women were enrolled out of which 51 were primigravida and 49 multigravidas.

Women of age 18 years to 36 years were enrolled in the study group.

Maternal and pregnancy characteristics of women in the study population is as follows.

In the study group majority (57) women were in the age group of 23-27 years, 34 women were in the age group of 18-22 years, 7 women were in the age group of 28-32 years, only 2 women were in the age group of 33-36 years (Table 1).

\section{Table 1: Age distribution of women in study} population.

\begin{tabular}{|ll|}
\hline Age group & Study population N (100) \\
\hline $18-22$ & 34 \\
\hline $23-27$ & 57 \\
\hline $28-32$ & 7 \\
\hline $33-36$ & 2 \\
\hline
\end{tabular}

In the study group, majority of women $(33 \%)$ enrolled were in their $41^{\text {st }}$ week of gestation, $22 \%$ women had completed 41 weeks 4 days , $12 \%$ of women were in their 41 weeks 3 days, $8 \%$ women were 41 weeks 2 days gestation and only $4 \%$ of women were in their 41 weeks 1 day and 41 weeks 6 days respectively (Table 2).

Mean age of women in the study group was 23.79 years (Table 3). 
Table 2: Gestational age of women in study group.

\begin{tabular}{|ll|}
\hline $\begin{array}{l}\text { Gestational age - weeks } \\
(410 / 7-416 / 7)\end{array}$ & Study population \\
\hline $410 / 7$ & 33 \\
\hline $411 / 7$ & 4 \\
\hline $412 / 7$ & 8 \\
\hline $413 / 7$ & 12 \\
\hline $414 / 7$ & 22 \\
\hline $415 / 7$ & 17 \\
\hline $416 / 7$ & 4 \\
\hline
\end{tabular}

Table 3: Mean maternal age and Gestational age of women in the study group.

\begin{tabular}{ll} 
Age group & Mean $( \pm 2$ SD) Percentage \\
Mean Maternal age (years) & 23.79 \\
\hline $\begin{array}{l}\text { Mean gestational }( \pm 2 \text { SD) } \\
410 / 7 \text { to } 416 / 7 \text { wks. }\end{array}$ & $41 \pm 1$ week \\
\hline
\end{tabular}

Mean gestational age of women in study group was $41+/-$ 1 week (Table 3 ).

About $51 \%$ of women in the study population were primigravida and $49 \%$ were multigravida (Table 4 ).

Table 4: Obstetric Index in study population.

\begin{tabular}{|ll|}
\hline Obstetric index & $\%$ \\
\hline Primigravida & 51 \\
\hline Multigravida & 49 \\
\hline
\end{tabular}

\section{DISCUSSION}

Induction of labour in late term pregnancy is a common accepted method for initiation of labour pains for vaginal delivery. Few studies have been done where Mifepristone is used for induction of labour. Hapangama and Neilson reported that a single dose of $200 \mathrm{mg}$ mifepristone appears to be the lowest effective dose for cervical ripening. ${ }^{8}$ In our study, Mifepristone $200 \mathrm{mg}$ was chosen for induction of labour.

Out of 51 primigravida in the study group, 6 women progressed in their Bishop score and delivered within 48 hours of induction, 37 women progressed and delivered after 48 hours of induction. 4 women did not show any improvement in bishops score even after 48hours of induction and underwent caesarean section. 4 women who had good improvement in Bishop score underwent caesarean section because of other indications like fetal distress, arrest in second stage etc (Table 5).

Out of 49 multigravidas in the study group ,4 women showed improvement in Bishops score within 24 hours of induction and delivered vaginally.35 and 10 women showed improvement in Bishop score within 24- 48 hours and after 48 hours respectively (Table 5).
Majority (73.5\%) of multigravida in the study group went into spontaneous labour within 48hours of treatment. In 4 women $(8.2 \%)$, induction delivery interval was less than 24 hours. Only $9(18.4 \%)$ women had prolonged induction delivery interval (Table 6).

Table 5: Bishop score analysis in study group.

\begin{tabular}{|c|c|c|c|c|}
\hline Parity (N) & $\begin{array}{l}\text { Bishop } \\
\text { score }\end{array}$ & $\begin{array}{l}0-24 \\
\text { hour } \\
(\mathrm{N})\end{array}$ & $\begin{array}{l}24-48 \\
\text { hours } \\
(\mathrm{N})\end{array}$ & $\begin{array}{l}>48 \\
\text { hours } \\
(\mathrm{N})\end{array}$ \\
\hline \multirow{3}{*}{$\begin{array}{l}\text { Primigravida } \\
(51)\end{array}$} & $<3$ & 51 & 4 & 4 \\
\hline & $4-6$ & 6 & 41 & 0 \\
\hline & $7-9$ & 0 & 06 & 37 \\
\hline \multirow{3}{*}{$\begin{array}{l}\text { Multi } \\
\text { gravida } \\
(49)\end{array}$} & $<3$ & 49 & 0 & 0 \\
\hline & $4-6$ & 0 & 9 & 0 \\
\hline & $7-9$ & 4 & 35 & 10 \\
\hline
\end{tabular}

Table 6: Induction delivery interval in primigravida and multigravida in study group.

\begin{tabular}{|llll|}
\hline $\begin{array}{l}\text { Induction } \\
\text { delivery } \\
\text { interval }\end{array}$ & $\begin{array}{l}\text { Primigravida } \\
\mathrm{n}=51(\%)\end{array}$ & $\begin{array}{l}\text { Multigravida } \\
\mathrm{n=49}(\%)\end{array}$ & $\begin{array}{l}\mathrm{P} \\
\text { value }\end{array}$ \\
\hline $0-24 \mathrm{hrs}$ & 0 & $4(8.2)$ & - \\
\hline $24-48 \mathrm{hrs}$ & $10(19.6)$ & $36(73.5)$ & $<0.01$ \\
\hline$>48 \mathrm{hrs}$ & $41(80.4)$ & $9(18.4)$ & $<0.01$ \\
\hline
\end{tabular}

Majority $41(80.4 \%)$ of primigravida had long induction delivery interval compared to multigravidas $10(19.6 \%)$ women progressed fast with induction delivery interval of less than 48 hours (Table 6).

The observation made in the study was prolonged induction delivery interval and patients required long hospital stay, especially primigravida's. However, women can be given oral mifepristone on outpatient basis and baby movements monitored by daily fetal kick count and non-stress test to reduce the hospital stay.

In a study conducted by Hapangama D et al, Mifepristone treated women were in labour or had favourable cervix at 48 hours (risk ratio (RR) $2.41,95 \%$ confidence intervals (CI) 1.70 to 3.42$).{ }^{8}$ Kanan Yelikar et al, observed reduction in mean induction delivery interval time, significant improvement in Bishop score in study group and significant percentage of women in Control Group delivered vaginally within $24 \mathrm{~h}$ without any need of augmentation. ${ }^{10}$ Atawale et al, also noted the significant change in Bishop score with the use of oral mifepristone. ${ }^{11}$

In our study $19.6 \%$ primigravida, $73.5 \%$ multigravida had induction delivery interval within $24-48 \mathrm{hrs}$ and $80.4 \%$, $18.4 \%$ of primigravida and multigravida respectively had 
long induction delivery interval of more than 48 hours (Table 6).

In the study group 4 multigravida delivered within 24hours of induction. Majority of multigravida (73.5\%) progressed and delivered within 48 hours. $80.4 \%$ of primigravida progressed to labour after 48 hours. $8.2 \%$ of multigravida progressed to labour within 24 hours (Figure 1).

Induction of labour with mifepristone in multigravida resulted in less time interval for spontaneous onset of labour from the time of induction. Majority of primigravida showed favourable response to induction with mifepristone though the time interval for spontaneous onset of labour was comparatively more than multigravidas.

Mean induction delivery interval was $38 \mathrm{hrs} 11 \mathrm{~min}$ which was comparable to Stenlund and Wing study. Mifepristone is an efficient drug for induction of labour in late term pregnancies (Table 7).

- Primigravida Vaginal delivery $-84.31 \%$

- Primigravida LSCS $-15.68 \%$

- Multigravida Vaginal delivery $-89.79 \%$

- Multigravida LSCS $-10.20 \%$

Majority of the women (84.31\%primigravida, $89.79 \%$ multigravida) in the study group had vaginal deliveries (Table 8).

Induction of labour with mifepristone in late term pregnancy results in significant vaginal deliveries.

Only 13 women in the study group underwent cesarean section which was comparable to Stenlund study (Table 9).

Majority $(84.31 \%)$ of primigravida had vaginal deliveries.44 out of 49 multigravida (89.79\%) had vaginal delivery (Figure 2).

$15.68 \%$ primigravida and 10.20 multigravida underwent cesarean section (Figure 2).

\section{CONCLUSION}

Mifepristone, a progesterone antagonist causes a significant improvement in the Bishop's score and is associated with an increase in the chance of vaginal delivery. Multigravida women showed significant improvement in their Bishop score following induction and they had less induction delivery interval compared to primigravida. Majority of Primigravida showed significant improvement in Bishop score and many had vaginal deliveries. Prolonged hospital stay can be reduced by administering tablet mifepristone $200 \mathrm{mg}$ orally on outpatient basis and monitoring the fetal movements by kick count and non-stress test. Mifepristone can be considered as an efficient drug for induction of labour in late term pregnancy.

\section{ACKNOWLEDGMENTS}

Authors gratefully acknowledge the voluntary and active participation of all study subjects. Authors are very much thankful to all the officials for allowing us to conduct the study. Authors acknowledge the great help received from the scholars whose articles cited and included in references of this manuscript.

\section{Funding: No funding sources}

Conflict of interest: None declared

Ethical approval: The study was approved by the Institutional Ethics Committee

\section{REFERENCES}

1. American College of Obstetricians and Gynaecologists. Practice bulletin no. 146: Management of late-term and post term pregnancies. Obstetric Gynecol. 2014;124(2 Pt 1):390-6.

2. Aaron B. Caughey, Naomi E. Stotland, A. Eugene Washington, and Gabriel J. scobar. Maternal Complications of Pregnancy Increase Beyond 40 Weeks' Gestation. Am J Obstet Gynecol. 2007 Feb; 196(2):155.e1-e6.

3. Olesen AW, Westergaard JG, Olsen J. Perinatal and maternal complications related to postterm delivery: a national register-based study, 1978-1993. Am J Obs Gynecol. 2003;189(1):222-7.

4. M. Galal, I. Symonds, H. Murray, F. Petraglia, and R. Smith. Postterm pregnancy. Facts Views Vis Obgyn. 2012;4(3):175-87.

5. Gülmezoglu AM, Crowther CA, Middleton $\mathrm{P}$, Heatley E. Induction of labour for improving birth outcomes for women at or beyond term. Cochrane Database Syst Rev. 2012 Jun 13;(6):CD004945.

6. Reelkar P, Solunke A, Aher G, Shinde U. Study of Use of Single Dose of Oral Mifepristone in Induction of Labour. Scholars J Applied Med Sci (SJAMS). Apr 2018; 6(4):1796-1800.

7. Heikinheimo O, Kekkonen R, La“hteenma“ki P. The pharmacokinetics of mifepristone in humans reveal insights into differential mechanisms of antiprogestin action. Contraception. 2003;68(6):421-6.

8. Hapangama D,Neilson JP. Cochrane Database Syst Rev. 2009(3):CD002865.

9. Clark K, Ji H, Feltovich H, Janowski J, Carroll C, Chien EK. Mifepristone-induced cervical ripening: Structural, biomechanical, and molecular events. Am J Obstet Gynecol. 2006;194(5):1391-8.

10. Yelikar K, Deshpande S. Safety and Efficacy of Oral Mifepristone in Pre-induction Cervical Ripening and Induction of Labour in Prolonged Pregnancy. J Obs Gynecol India. 2015 July-august;65(4):221-5. 
11. Athawale R, Acharya N, Samal S, Hariharan C. Effect of mifepristone in cervical ripening for induction of labour. Int $\mathrm{J}$ Reprod Contracept Obstet Gynecol. 2013;2(1):35-8.

12. Stenlund PM, Ekman G, Aedo AR, Bygdeman M. Induction of labor with mifepristone, -A randomized, double-blind study versus placebo. Acta Obstet Gynecol Scand. 1999;78(9):793-8.

13. Wing DA, Fassett MJ, Mishell Jr DR. Mifepristone for preinduction cervical ripening beyond 41 weeks' gestation: a randomized controlled trial. Obstet Gynecol. 2000;96(4):543-8.

Cite this article as: Roopa NK, Rekha N. Efficacy of Mefipristone for induction of labour in late term pregnancy. Int J Reprod Contracept Obstet Gynecol 2019;8:2384-8. 